\title{
Análise de imagem de pães tipo forma: relação entre a incorporação de pós não-formadores de glúten e a estrutura do miolo
}

\author{
R. A. ZAMBELLI ${ }^{1}$, J. D. R. VIANA¹, C. A. R. LIMA¹, D. L. BRASIL ${ }^{1}$, PINHEIRO, G. K. ${ }^{1}$, \\ D. F. PONTES ${ }^{1}$.
}

${ }^{1}$ Universidade Federal do Ceará, Departamento de Tecnologia de Alimentos. E-mail para contato: Zambelli@alu.ufc.br

\begin{abstract}
RESUMO - O objetivo foi avaliar a estrutura do miolo de pães com adição de farinhas não-formadoras de glúten através de análise de imagem. Estudou-se a incorporação de tomate, brócolis, açaí em pó, polidextrose em formulações de pães, ao todo, foram desenvolvidas 7 formulações. Fotografias tiradas de fatias de $20 \mathrm{~mm}$ de espessura, foram digitalizadas e convertidas para tons de cinza (8-bit) pelo programa ImageJ® e limiarizadas por meio do algorítimo de otsu. A partir disto foi possível obter os número de alvéolos, sua área e perímetro médio, bem como a circularidade. Verificou-se que a incorporação de tomate em pó e polidextrose em níveis de $5 \%$ aumentou o número de alvéolos, reduzindo a área e o perímetro, com o aumento da circularidade, que foi de 0,850. A adição dos ingredientes, sobretudo do brócolis e açaí em pó, superior a $10 \%$ produziu a redução dos alvéolos, prejudicando a estrutura do miolo.
\end{abstract}

\subsection{INTRODUÇÃO}

A polidextrose é um polímero de glicose desenvolvido em 1960, foi polimerizado aleatoriamente com cadeias ramificadas e possui vários tipos de ligações glicosídicas que não são digeridas por enzimas digestivas humanas (RANINEN et al., 2011). Possui poder calorífero baixo, com $1 \mathrm{kcal}$ a cada grama de polidextrose, tendo demonstrado efeito fisiológico semelhante ao das fibras dietéticas (HENGST et al., 2008), sendo parcialmente fermentado pela microbiota do intestino.

Dentre os benefícios comprovados do açaí em pó estão a capacidade de reduzir o colesterol, conforme estudo desenvolvido por Souza et al. (2012), onde foi observada a redução dos níveis de colesterol em ratos alimentados com polpa de açaí, resultante do aumento da taxa de excreção biliar e de esteróis, com o aumento da captação de LDL pelo fígado por meio do aumento da regulação do LDL-R. Fragoso et al. (2013) verificaram que o açaí em pó, em proporções de $5 \%$, pode reduzir o desenvolvimento de processos de carcinogênese quimicamente induzido em cólon de ratos wistar. Possui efeito neuroprotetor in vitro, com a inibição da agregação de $\beta$-amilóide, conforme estudo apresentado por Wang et al. (2013).

Devido ao seu elevado poder antioxidante, o tomate em pó tem sido amplamente utilizado em muitos estudos e preparações alimentícias (TUZCU et al., 2012). Estes autores provaram que a suplementação com tomate em pó impediu o crescimento e a incidência de câncer colorretal em ratos wistar, desempenhando um papel importante contra o estresse 
oxidativo, podendo ser um potencial candidato na prevenção deste tipo de tumor em seres humanos.

Fahey et al. (2003) relataram que o brócolis é uma das fontes mais ricas na promoção da saúde através de glucosinolatos, antioxidantes e nutrientes essenciais como fonte de fibra diética total $(3,0 \mathrm{~g} / 100 \mathrm{~g})$, cálcio $(48 \mathrm{mg} / 100 \mathrm{~g})$, magnésio $(25 \mathrm{mg} / 100 \mathrm{~g})$, selênio $(3,0 \mu \mathrm{g} / 100$ $\mathrm{g})$, zinco $(0,4 \mathrm{mg} / 100 \mathrm{~g})$, ácido ascórbico $(93,2 \mathrm{mg} / 100 \mathrm{~g})$, ácido fólico $(71 \mu \mathrm{g} / 100 \mathrm{~g})$ e $\beta$ caroteno $(779 \mu \mathrm{g} / 100 \mathrm{~g})$.

O estudo tem como objetivo avaliar a influência da incorporação de pós alimentícios não formadores de glúten em formulações de pães tipo forma e, através de análise de imagem, estudar os efeitos na estrutura do miolo.

\subsection{METODOLOGIA}

As formulações de pães tipo forma desenvolvidas, com a incorporação de açaí, brócolis e tomate em pó, bem como de polidextrose são apresentadas na tabela 1.

Tabela 37 - Formulações de pães tipo forma desenvolvidas.

\begin{tabular}{cccccccc}
\hline Ingredientes (\%) & Padrão & T1 & T2 & B1 & B2 & A1 & A2 \\
\hline Farinha de Trigo & $100 \%$ & $100 \%$ & $100 \%$ & $100 \%$ & $100 \%$ & $100 \%$ & $100 \%$ \\
Água* & $58-62 \%$ & $58-$ & $58-62 \%$ & $58-62 \%$ & $58-$ & $58-$ & $58-62 \%$ \\
& & $62 \%$ & & & $62 \%$ & $62 \%$ & \\
Gordura Vegetal & $10 \%$ & $10 \%$ & $10 \%$ & $10 \%$ & $10 \%$ & $10 \%$ & $10 \%$ \\
$\quad$ Hidrogenada & & & & & & & \\
Açúcar Refinado & $5 \%$ & $5 \%$ & $5 \%$ & $5 \%$ & $5 \%$ & $5 \%$ & $5 \%$ \\
$\quad \begin{array}{c}\text { Fermento } \\
\text { Biológico }\end{array}$ & $3,3 \%$ & $3,3 \%$ & $3,3 \%$ & $3,3 \%$ & $3,3 \%$ & $3,3 \%$ & $3,3 \%$ \\
Polidextrose & - & $5 \%$ & $10 \%$ & $5 \%$ & $10 \%$ & $5 \%$ & $10 \%$ \\
Tomate em pó & - & $5 \%$ & $10 \%$ & - & - & - & - \\
Brócolis em pó & - & - & - & $5 \%$ & $10 \%$ & - & - \\
Açaí em pó & - & - & - & - & - & $5 \%$ & $10 \%$ \\
\hline
\end{tabular}

* Com base no percentual de absorção de água de cada farinha.

\subsection{Processamento dos Pães Tipo Forma}

Os ingredientes foram pesados em balança semi-analítica separadamente. Aplicou-se o método direto, onde todos os ingredientes são colocados simlutaneamente no início da etapa de mistura, com exceção do sal e água. Eles foram misturados em misturadora de escala semiindustrial durante 1 minuto em baixa velocidade para a homogeneização dos ingredientes, em seguida foi adicionada a água e misturada por 3 minutos em velocidade média, por último foi adicionado o sal e a massa foi misturada em alta velocidade por 6 minutos até o seu completo desenvolvimento. As massas foram divididas em porções de $250 \mathrm{~g}$ e moldadas na forma de elipses manualmente. Foram colocadas em fôrmas de folha galvanizada de ferro de chapa única para pão de forma sem tampa. Em seguida, colocadas em câmara de fermentação regulada a temperatura de $28{ }^{\circ} \mathrm{C} \pm 2{ }^{\circ} \mathrm{C}$ e $80 \%$ de umidade relativa, durante uma hora e trinta minutos. Ao final da fermentação, as massas foram assadas sem vapor durante 20 minutos a 
temperatura de $220^{\circ} \mathrm{C}$ em forno elétrico de lastro Continental Advance Turbo®. Os pães foram resfriados durante uma hora em temperatura ambiente.

\subsection{Avaliação de imagem do miolo de pães tipo forma}

As estruturas dos miolos dos pães foram avaliadas através de imagens digitais segundo metodologia descrita por Rosales-Juárez et al. (2008); Gonzales-Barrón e Butler (2006) com modificações. As imagens foram obtidas por digitalização em resolução de 550 dpi em scanner HP ScanJet 2400, na área central do miolo com resolução de 900x900 pixels. As imagens obtidas foram analisadas com o software ImageJ ${ }^{\circ} 1.47 \mathrm{v}$ (National Institute of Health, USA). As Imagens foram salvas como arquivos em formato de jpeg e foram cortadas para um campo de vista de 900x900 mm, as imagens coloridas capturadas foram convertidas para 8-bit em tons de cinza, onde foi realizada a limiarização por meio do algorítimo de Otsu. A partir disto, foi possível obter os valores do número de alvéolos, área, perímetro e circularidade dos poros.

\subsection{Análise Estatística}

A avaliação dos resultados dos parâmetros estruturais do miolo de pães tipo forma foi realizada por análise de variância (ANOVA) e aplicado o teste de médias ao nível de 5\% de significância para verificar diferenças significativas entre os tratamentos. A análise foi realizada no programa STATISTICA 7.0.

\subsection{RESULTADOS E DISCUSSÃO}

A tabela 2 apresenta os valores obtidos para os parâmetros estruturais do miolo dos pães tipo forma.

Tabela 2 - Parâmetros estruturais do miolo de pães tipo forma.

\begin{tabular}{ccccc}
\hline Formulação & $\begin{array}{c}\text { Número de } \\
\text { alvéolos (cel) }\end{array}$ & $\begin{array}{c}\text { Área média dos } \\
\text { alvéolos }\left(\mathbf{m m}^{2}\right)\end{array}$ & $\begin{array}{c}\text { Perímetro } \\
\text { médio dos } \\
\text { alvéolos }\left(\mathbf{m m}^{\mathbf{2}}\right)\end{array}$ & $\begin{array}{c}\text { Circularidade } \\
\text { dos alvéolos }\end{array}$ \\
\hline Padrão & $838^{\mathrm{c}} \pm 17$ & $396,19^{\mathrm{c}} \pm 1,15$ & $456,22^{\mathrm{e}} \pm 7,36$ & $0,849^{\mathrm{d}} \pm 0,01$ \\
T1 & $1025^{\mathrm{b}} \pm 21$ & $361,46^{\mathrm{f}} \pm 2,25$ & $497,33^{\mathrm{c}} \pm 3,11$ & $0,855^{\mathrm{c}} \pm 0,03$ \\
T2 & $638^{\mathrm{d}} \pm 17$ & $413,22^{\mathrm{b}} \pm 2,43$ & $527,47^{\mathrm{b}} \pm 2,19$ & $0,803^{\mathrm{g}} \pm 0,03$ \\
B1 & $1102^{\mathrm{a}} \pm 11$ & $355,10^{\mathrm{d}} \pm 2,84$ & $435,31^{\mathrm{f}} \pm 3,11$ & $0,865^{\mathrm{b}} \pm 0,02$ \\
B2 & $636^{\mathrm{d}} \pm 11$ & $369,23^{\mathrm{e}} \pm 2,02$ & $437,09^{\mathrm{f}} \pm 3,57$ & $0,811^{\mathrm{f}} \pm 0,03$ \\
A1 & $845^{\mathrm{c}} \pm 12$ & $399,15^{\mathrm{c}} \pm 2,11$ & $474,22^{\mathrm{d}} \pm 2,73$ & $0,894^{\mathrm{a}} \pm 0,01$ \\
A2 & $618^{\mathrm{d}} \pm 19$ & $511,73^{\mathrm{a}} \pm 2,21$ & $648,27^{\mathrm{a}} \pm 1,73$ & $0,832^{\mathrm{e}} \pm 0,03$ \\
\hline
\end{tabular}

${ }^{1}$ Médias com letras minúsculas iguais na mesma linha não diferem estatisticamente $(\mathrm{p} \leq 0,05)$ entre si.

Padrão: formulação sem a adição dos ingredientes funcionais; Açaí 1 (A1): $5 \%$ de açaí em pó e polidextrose; Açaí 2 (A2): $10 \%$ de açaí em pó e polidextrose; Brócolis 1 (B1): 5\% de brócolis e polidextrose; Brócolis 2 (B2): $10 \%$ de brócolis em pó e polidextrose; Tomate 1 (T1): $5 \%$ de tomate em pó e polidextrose; Tomate 2 (T2): $10 \%$ de tomate em pó e polidextrose. 
Com relação ao número de alvéolos, não houve diferença significativa, ao nível de 5\% de significância entre as formulações padrão e A1, bem como entre T2, B1 e A2. Para a área média dos alvéolos, não apresentaram diferenças significativas a formulação padrão e A1. O perímetro médio dos alvéolos das formulações adicionadas de polidextrose e brócolis em pó, B1 e B2, não apresentaram diferenças significativas entre si, enquanto que para a circularidade dos alvéolos, todas as formulações desenvolvidas apresentaram diferença significativa ao nível de 5\% de significância.

A incorporação dos ingredientes funcionais, em quantidades de $5 \%$, proporcionaram melhor distribuição do número de alvéolos, quando comparados à formulação padrão, que apresentou 838 alvéolos, o maior valor apresentado foi pela formulação B1, com 1102, seguido de T1, com 1025 e A1 com 845 alvéolos, isto se deve ao fato de um processo fermentativo melhor conduzido, provavelmente pela maior disponibilidade de nutrientes para as leveduras devido à incorporação dos ingredientes funcionais, que, na quantidade de 5\% de incorporação, não foi observado danos à rede do glúten.

Entretanto, quando a adição foi de $10 \%$ dos ingredientes funcionais houve a redução do número de alvéolos, onde todas as formulações apresentaram valores inferiores à formulação padrão, sem a incorporação dos ingredientes funcionais, o menor valor apresentado foi pela formulação A2, com 618 alvéolos. A formação de uma estrutura do miolo mais densa, com menor quantidade de alvéolos, sugere danos à rede do glúten, uma vez que estes pós alimentícios, além de serem rico em fibras, enfraquecem a rede formada, além de prejudicar o processo de fermentação.

Segundo Almeida (2012), a formação das células de gás, cerca de 8\%, acontece durante a etapa de mistura da massa, havendo a incorporação de ar, que, possue uma composição de $79 \%$ de nitrogênio e $21 \%$ de oxigênio, durante a fermentação este oxigênio é consumido pelas leveduras e o $\mathrm{CO}_{2}$ é difundido na massa através de um equilíbrio de fases entre a fase líquida e gasosa, posteriormente ocorre uma elevação da pressão e o $\mathrm{CO}_{2}$ passa totalmente para o estado gasoso, elevando o volume dos pães e fornecendo pressão às células de gás, futuros alvéolos, que serão preenchidos com o gás carbônico e expandidos durante o forneamento, levando à sua formação. A incorporação de fibras ou minerais ocasionam má formação ou enfraquecimento da rede do glúten, permitindo que este gás carbônico escape, não formando alvéolos, por isto, neste estudo, atribuiu-se ao elevado conteúdo mineral e de fibras do açaí a formação do menor número de alvéolos.

Pela redução do número de alvéolos considera-se que o miolo ficou mais denso, o que é notório pelo aumento da área e perímetro médio dos alvéolos. Para a formulação padrão, os valores observados foram de $396,19 \mathrm{~mm}^{2}$ e $456,22 \mathrm{~mm}^{2}$. Com a incorporação do tomate em pó e da polidextrose houve a elevação da área e perímetro dos alvéolos de $361,46 \mathrm{~mm}^{2}$ e $497,33 \mathrm{~mm}^{2}$ para $413,22 \mathrm{~mm}^{2}$ e $527,47 \mathrm{~mm}^{2}$, respectivamente.

Os maiores valores observados foram para a formulação A2, obtendo $511,73 \mathrm{~cm}^{2}$ de área e $648,27 \mathrm{~mm}^{2}$ de perímetro. Através da figura 2, pode-se observar a formação de fendas pela junção de alvéolos e o consequente aumento da área e do perímetro dos diversos alvéolos produzidos durante o processo de fermentação. 
O efeito do uso combinado do brócolis em pó e polidextrose promoveu menores alterações na área e perímetro médio dos alvéolos, os maiores valores foram observados para B2, que obteve $369,23 \mathrm{~mm}^{2}$ e $437,09 \mathrm{~mm}^{2}$. A combinação dos ingredientes açaí em pó e polidextrose em formulações de pães tipo forma promoveu o maior aumento da área e perímetro médio quando adicionado nas quantidades de $10 \%$, os valores obtidos foram de $511,73 \mathrm{~mm}^{2}$ e $648,27 \mathrm{~mm}^{2}$.

A figura 1 apresenta a imagem digital limiarizada de amostra de miolo de pão tipo forma A2.

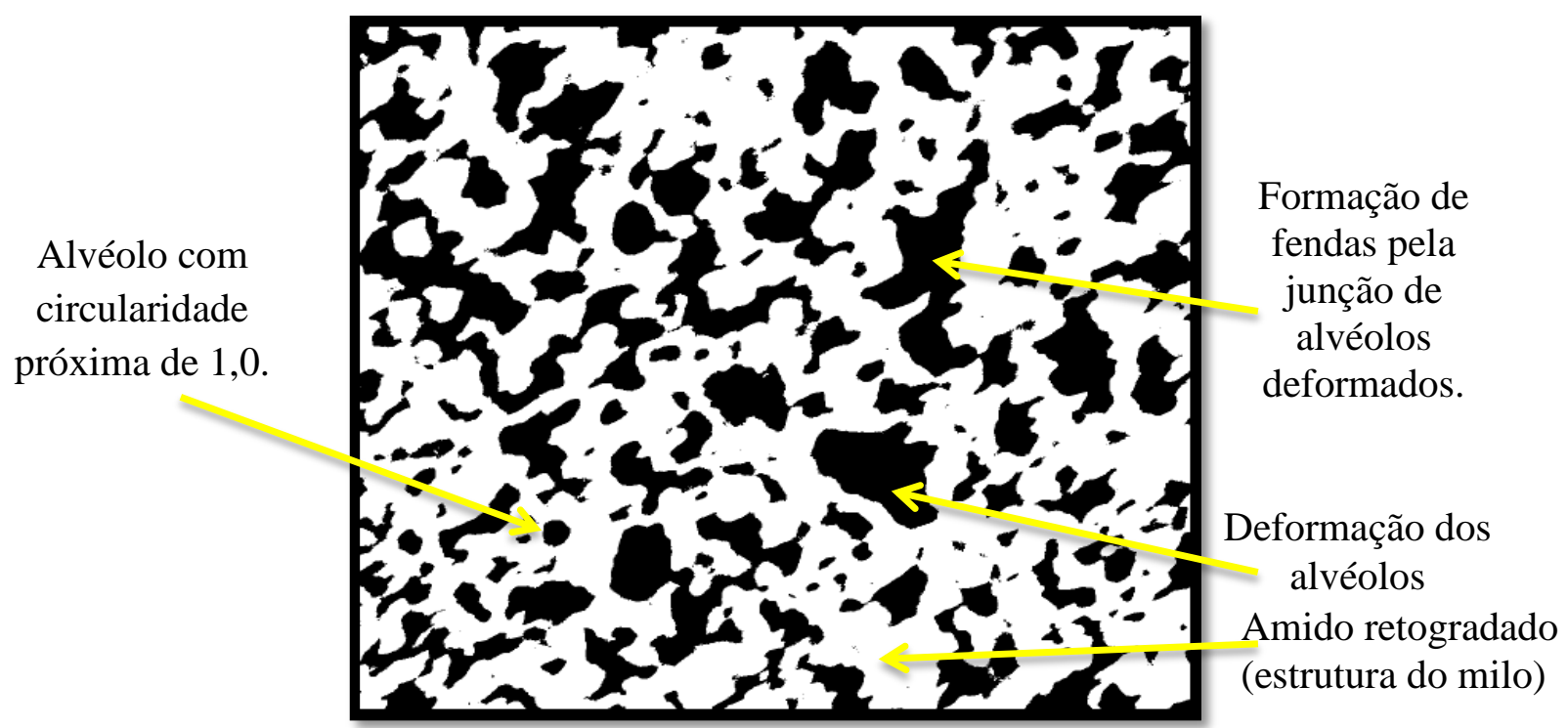

Figura 1 - Imagem digital limiarizada $(900 \times 900 \mathrm{~mm})$ de amostras do miolo de pão tipo forma A2

A figura 2 apresenta a imagem digital limiarizada de amostra de miolo de pão tipo forma padrão.

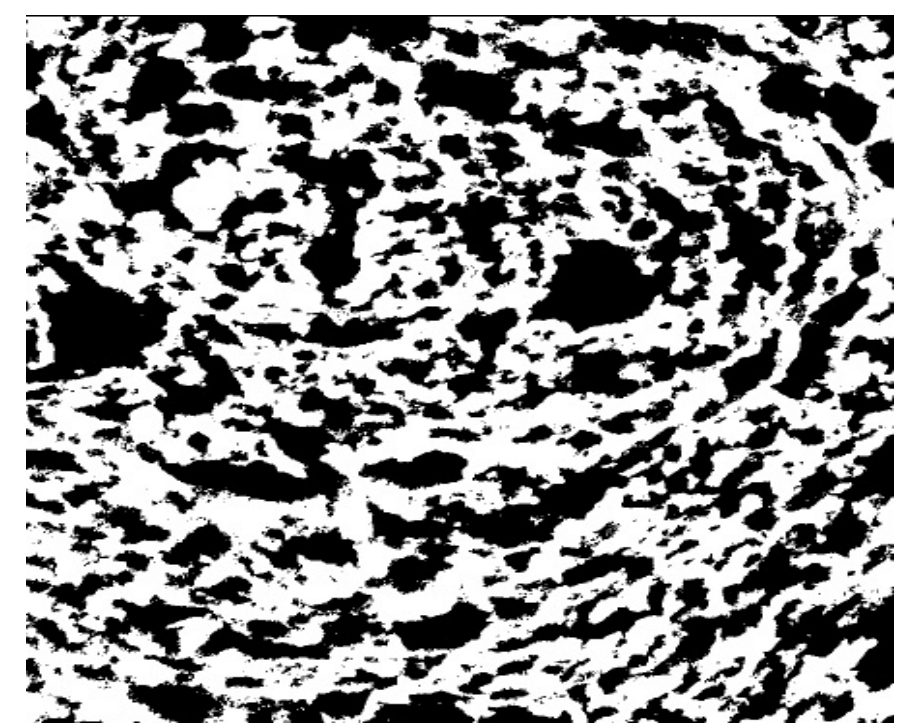

Figura 2- Imagem digital limiarizada $(900 \times 900 \mathrm{~mm})$ de amostras do miolo de pão tipo forma padrão 
A circularidade é o parâmetro que mede o quanto os alvéolos se aproximam ou não de um círculo, seus valores a variam de 0 a 1 , onde representa o valor de um círculo perfeito (Rosell e Gomez, 2007). O grau de circularidade dos alvéolos foi reduzido em função do da incorporação dos ingredientes funcionais, os valores variaram de 0,803 (T2) a 0,894 (A1).

Matos e Rosell (2012) encontraram valores de circularidade de pães sem glúten variando de 0,64 a 0,81; valores próximos aos obtidos neste estudo com a adição de polidextrose e vegetais em pó.

Em estudo desenvolvido por Hager et al., (2012), investigando a estrutura do miolo de pães processados com diferentes matérias-primas sem glúten, como milho, amido, quinoa, arroz e etc, observaram que as formulações sem glúten apresentaram número de alvéolos inferior ao aos pães processados somente com farinha de trigo, diferentemente do que foi observado no estudo com a adição de polidextrose e vegetais em pó, onde as formulações T1, B1 e A1, ou seja, quando a incorporação foi de 5\%, obtiveram maior número de alvéolos do que a padrão.

Ao compararmos a figura 1 e 2 percebe-se que a formulação padrão apresenta maior distribuição alveolar do que a formulação A2, o que comprova o efeito danoso da polidextrose e açaí em pó nas proporções de $10 \%$ de incorporação, comportamento este também apresentado pelas formulações adicionadas de tomate em pó e brócolis em pó em conjunto com a polidextrose.

\subsection{CONCLUSÃO}

A adição de até 5\% dos ingredientes funcionais melhorou a distribuição dos alvéolos do miolo de pães tipo forma, quando a incorporação foi de $10 \%$ houve redução no número de alvéolos e no aumento de suas respectivas áreas e perímetros, indicando danos à rede do glúten e tornando o miolo mais denso.

\subsection{REFERÊNCIAS}

ALMEIDA, E. L.; CHANG, Y. K. Influence of different enzymes during the frozen storage of pre-baked French bread elaborated with whole-wheat flour. J. Food Process. Preserv, v. 67, n. 2, p. 38-45, 2012.

FAHEY, J. W. Brassicas. In: CABELLERO, B.; TRUGO, L.; FINGLA, S. P. (ed). Enc. Food Sci and Nutr.. Academic, St. Louis, p. 606-615, 2003.

FRAGOSO, M. F.; ROMUALDO, G. R.; RIBIERO, D. A.; BARBISA, L. F. Açai (Euterpe oleracea Mart.) feeding attenuates dimethylhydrazine-in-duced rat colon carcinogenesis. Food and Chem. Toxicol., v. 58, n. 1, p. 68-76, 2012.

GONZALES-BARRÓN, U.; BUTLER, F. A comparison of seven thresolding techniques with the k-means clustering altorithm for measurement of bread-crumb features by digital image analysis. J. Food Eng., v. 74, n. 2, p. 268-278, 2006. 
HAGER, A.; WOLTER, A.; CZERNY, M.; BENZ, J.; ZANINI, B.; ARENDT, E. K.; CZERNY, M. Investigation of product quality, sensory profile and ultrastructure of breads made from a range of commercial gluten-free flours to their wheat counterparts. Eur. Food. Res. Technol., v. 235, n. 1, p. 333-444, 2012.

HENGST, C.; PTOK, S.; ROESSLER, A.; FECHNER, A.; JAHREIS, G. Effects of polydextrose supplemention on different faecal parameters in healthy volunteers. Int. J. Food Sci. and Nutr., v. 60, n. 5, p. 96-105, 2008.

MATOS, M. E.; ROSELL, C. M. Relationship between instrumental parameters and sensory characteristcs in gluten-free breads. Eur. Food. Res. Technol., v. 235, n. 1, p. 107-117, 2012.

RANINEN, K.; LAPPI, J.; MYKKANEN, H.; POUTAMEN, K. Dietary fiber type reflects physiological functionality: comparison of grain fiber, inulin and polydextrose. Nutr. Rev., v. 69, n. 2, p. 9-21, 2011.

ROSALES-JUÁREZ, M.; GONZÁLEZ-MENDONZA, B.; LÓPEZ-GUEL, E.; LOZANOBAUTISTA, F.; CHANONA-PÉREZ, J.; GUTIÉRREZ-LOPES, G.; FARRERA-REBOLLO, R.; CALDERÓN-DOMÍNGUEZ, G. Changes on dough rheological characteristics and bread quality as a result of the addition of germinated and non-germinated soybean flour. Food and Bio. Tech. v. 1, n. 2, p. 2008.

ROSELL, C. M.; GÓMEZ, M. Freezing in breadmaking performance: frozen dough and partbaked bread. Food Rev. Int., v. 23, n. 2, p. 303-139, 2007.

SOUZA, M. O.; SILVA, L. S.; MAGALHÃES, C. L. B.; FIGUEIREDO, B. B.; COSTA, D. C.; SILVA, M. E.; PEDROSA, M. L. The hypocholesterolemic activity of açaí (Euterpeoleracea Mart.) is mediated by the enhanced expression of the ATP-binding cassette, subfamily G transporters 5 and 8 and low-density lipoprotein receptor genes in the rat. Nut. Res. v. 32, n. 1, p. 976-984, 2012.

TUZCU, M.; ASLAN, A.; TUZCU, Z.; YABAS, M.; BAHCECIOGLU, I. H.; OZERCAN, I. H.; KUCUK, O.; SAHIN, K. Tomato powder impedes the development of azoxymethaneinduce colorectal cancer in rats through suppression of COX-2 expression via NF-kB and regulating Nrf2/HO-1 pathway. Mol. Nutr. And Food Res., v. 56, n. 1, p. 1477-1481, 2012.

WANG, D. Y. S.; MUSGRAVE, I. F.; HARVEY, B. S.; SMID, S. D. Açaí (Euterpe oleraceae Mart.) berry extract exerts neuroprotective effects against $\beta$-amyloid exposure in vitro.

Neurosci. Let., v. 556, n. 3, p. 221-226, 2013. 